\title{
PEDAGOGIAS EMANCIPADORAS E NOVOS SENTIDOS DE COMUNIDADE NA AMÉRICA LATINA
}

\author{
EMANCIPATORY PEDAGOGIES AND NEW SENSES OF \\ COMMUNITY IN LATIN AMERICA
}

\author{
Alfonso Torres Carrillo*
}

RESUMO: Este trabalho apresenta uma reflexão a respeito dos discursos, das práticas e dos atores educacionais alternativos, tanto históricos quanto emergentes, identificando algumas características comuns e referentes discursivos convergentes que anunciam e expressam a emergência de novos imaginários e paradigmas de transformação social.

Palavras-chave: Pedagogia emancipadora; Comunidade; Alternativas pedagógicas; América Latina.

ABSTRACT: This paper presents a reflection on alternative, historical, and emerging educational discourses, practices and actors. The author identifies some common features and convergent discursive referents that announce and express the emergence of new imaginaries and social transformation paradigms.

Keywords: Emancipatory pedagogy; Community; Pedagogical alternatives; Latin America.

\section{APRESENTAÇÃO}

Onde iremos buscar modelos? A América espanhola é original. Original devem ser suas instituições e seus governos. E originais devem ser os meios de fundar uns e outros. Ou inventamos ou erramos.

Simón Rodríguez

Nas últimas cinco décadas, nosso continente latino-americano foi cenário de emergência de uma pluralidade de propostas, concepções e correntes pedagógicas que se dissociam dos modelos educacionais hegemônicos, ao passo que são configuradas como alternativas a tais paradigmas.

\footnotetext{
* Realizou pós-doutorado na Universidade Pedagógica Nacional (Colômbia) e doutorado em Estudos Latino-americanos pela Universidade Autônoma do México (UNAM). Docente da Universidade Pedagógica Nacional. Contato: alfonsitorres@gmail.com
} 
Sem desconhecer as ideias e experiências educacionais de Dom Simón Rodríguez na aurora do período republicano, nas universidade de trabalhadores e populares do início do século XX e a Escola Ayullú em Warisata (Bolívia), há um consenso de reconhecer na chamada educação conscientizadora - também conhecida como problematizadora ou libertadora -, iniciada por Paulo Freire no começo dos anos 1960 e sistematizada há cinquenta anos, a primeira proposta pedagógica alternativa que ultrapassou os marcos territoriais de sua emergência até se converter em uma corrente de alcance mundial.

A partir da recepção e da ressignificação das propostas educativas de Freire nas décadas seguintes, em um contexto sociopolítico marcado pela ascensão das lutas sociais e influência de ideias revolucionárias na política, nas ciências sociais e na cultura, surgiu uma diversidade de práticas educacionais e de coletivos de educadores que se identificaram como educação popular. Essa nova concepção pedagógica foi configurada como um movimento educacional comprometido com a transformação social a partir do empoderamento de diferentes setores sociais em condição de subordinação, exclusão ou discriminação.

Este contexto social e ideológico, que era encarnado nas experiências políticas da Unidade Popular no Chile e na Revolução Sandinista na Nicarágua, implicou que, em um primeiro momento, aqueles que pretendiam fazer educação popular privilegiassem o trabalho com populações de classes subalternas, fossem camponeses, trabalhadores ou moradores de bairro, em torno de seus problemas e direitos econômicos e sociais.

À medida que outros problemas emergiam e eram reconhecidos - por exemplo, em relação aos direitos humanos, à democracia, ao meio ambiente, às identidades culturais e de gênero - e outros setores da população se uniram à luta - mulheres, jovens, camponeses, afrodescendentes, indígenas, LGBTI -, a educação popular ampliou seus referenciais e incorporou outras ideias, princípios e critérios pedagógicos provenientes do feminismo, das perspectivas de gênero, do ambientalismo e da interculturalidade, enriquecendo e pluralizando o leque de propostas educacionais - educação popular entre mulheres, educação ambiental popular, entre outras.

Aguns movimentos sociais, por sua vez, geraram suas próprias propostas educacionais, a partir da singularidade de seus problemas, suas identidades 
sociais e seus referenciais culturais e programáticos, nomeando-as com novos qualificativos, tais como "educação própria" e "educação comunitária" - povos indígenas e afro -, pedagogia do campo e do movimento - movimentos camponeses do Brasil, como MST e MTTR. Em alguns casos, essas iniciativas reconhecem a influência de Freire e da educação popular; outras insistem em sua autenticidade e singularidade.

Também tem sido configurados outros discursos e práticas educacionais e pedagógicas como resultado da transposição e da recriação de novos paradigmas emancipadores ou movimentos sociais e políticos emergentes, tais como a decolonialidade, a interculturalidade, o ambientalismo, o neozapatismo, o bem viver, a comunalidade e a paz. Por isso encontramos hoje propostas e experiências educacionais como a pedagogia decolonial (Catherine Walsh), pedagogia da terra (Moacir Gadotti), pedagogia rebelde (zapatistas), pedagogia da resistência (Korol e Pañuelos en rebeldía) e a re-existência (Walsh, Albán), pedagogias insubmissas (Patricia Melgarejo), educação intercultural (movimentos étnicos e políticas educacionais), educação comunalitária (organizações e intelectuais indígenas de Oaxaca), pedagogia deneocolonial (Luis Bigott), pedagogias militantes (Coletivo Diatriba e Cooperativa de Educadores Populares), pedagogias da alteridade (Skliar e Larrosa), pedagogia da mãe terra (Abadio Green) e pedagogias da memória (Ortega, Rubio), entre outras.

Ainda que este não seja um mapeamento sistemático dos discursos, práticas e atores educacionais alternativos, históricos e emergentes, atrevo-me a identificar algumas características comuns e alguns referentes discursivos convergentes que, como assinalarei adiante, anunciam e expressam a emergência de novos imaginários e paradigmas de transformação social.

1. Crítica radical do sistema moderno capitalista e colonial. Para além dos conflitos, pressões e discriminações que tornam visíveis essas propostas educacionais advindas dos movimentos sociais e culturais que as sustentam, elas evidenciam e buscam transformar o sistema que as produz em conjunto. A globalização, imposta como ideologia e como política totalitária em escala mundial, evidencia que não é este ou aquele aspecto particular da ordem capitalista que está falhando, mas que é sua própria racionalidade unitária, 
homogeneizante, depredadora, excludente e opressiva que gera os múltiplos problemas dos quais hoje padece a humanidade.

2. Adoção, construção ou recriação de horizontes de sentido ou visões de futuro - alternativas, alterativas, utópicas e distópicas. Diante da impossibilidade de encontrar uma solução para as múltiplas formas de opressão e discriminação em torno das quais se enfileiram essas propostas educacionais, dentro dos marcos do sistema capitalista e da racionalidade instrumental moderna e colonial imperante, retoma-se e reafirma-se a necessidade de outros mundos possíveis que promovam o bem viver, a democracia e a justiça sob uma perspectiva a um só tempo ecológica e respeitadora das diferenças.

3. Transformação das subjetividades e dos sujeitos que possibilitem a realização conjunta dessas transformações e alterações no sistema, reconhecendo a riqueza de dimensões e sentidos que nos constitui como humanos: consciência, vontade, emotividade, corporalidade, amorozidade, ética e estética. Por isso, as propostas metodológicas e pedagógicas tendem a reconhecer essas dimensões e a potencializá-las em uma perspectiva emancipadora: oficinas interativas, passeios pelo território, cartografias corporais.

4. Promovem práticas educacionais e reflexões pedagógicas contextualizadas e enraizadas nas realidades dos sujeitos educativos em suas diferentes dimensões - pessoal, comunitária, local, regional. Assim como os movimentos e organizações a partir dos quais essas práticas são gestadas, elas dão grande importância ao territorial, entendido não apenas como espaços geográficos, mas como dimensões dos espaços corporais e existenciais. Desse modo, o princípio metodológico proveniente da educação popular, "partir da realidade", se expande e se torna mais complexo, envolvendo dimensões ambientais, culturais e espirituais.

5. Reconhecimento e confluência de diferentes saberes. As sabedorias ancestrais e populares reconhecem e enriquecem os saberes gestados a partir das práticas de resistência e da ação coletiva, das práticas artísticas e estéticas, dos conhecimentos técnico e científico e dos diversos modos de pensamento crítico. A partir da educação popular, chamamos isso de diálogo de saberes e diálogo cultural; a partir de Boaventura de Sousa Santos, chamamos isso de 
ecologia de saberes e, mais recentemente, alguns chamam de diálogo intercultural ou inter-epistêmico.

6. Defesa e produção de comunidade. Atualmente, os múltiplos discursos e práticas pedagógicas emergentes aludem à comunidade e ao comunitário. Isso não se refere mais apenas a populações pobres situadas em pequenos territórios, mas às diversas maneiras de estar e de viver em conjunto, ao estabelecimento de vínculos mais sólidos e aos diferentes sentidos de pertença que não aludem apenas ao comum, mas à diferença.

Toda essa discussão permite compreender que existem outros velhos e novos modos de estar e de atuar em conjunto que geram vínculos de solidariedade e compromisso em torno de práticas culturais, opções éticas e movimentos sociais nos quais participam pessoas de diferentes procedências e características. Muitas desses agrupamentos e ações são definidas como comunitárias em oposição às formas de vida, de relação, de pensamento e de consumo de caráter capitalista, que hoje penetram em todos os rincões do planeta e invadiram todas as esferas da vida social - cultura, comunicação, esporte, educação, emotividade, etc.

\section{EMERGÊNCIAS COMUNITÁRIAS NA AMÉRICA LATINA}

A mercantilização generalizada das relações sociais, levada ao extremo no modelo neoliberal, procura dissolver "toda forma de sociabilidade e a possibilidade de produzir livremente outras formas de vida que representa a confirmação recíproca da individualidade e da opção de atribuir fins comuns" (BARCELONA, 1999). Como "pensamento único", também busca impedir que surjam sujeitos e subjetividades coletivas portadores de outros projetos econômicos, sociais, políticos e alternativos à ordem capitalista.

Paralelamente, a mencionada expansão da dominação capitalista também viabilizou, reativou e possibilitou o surgimento de modos de vida, valores, vínculos, redes e projetos sociais que escapam da lógica individualista, competitiva e contratual. Ao menos na América Latina, tais dinâmicas e práticas sociais alternativas portam outros sentidos de comunidade. Por meio delas, emerge uma nova sociabilidade, bem como ações coletivas e modos de entender a democracia. 
O reconhecimento desses sentidos do comunitário pode dar alento a propostas e projetos alternativos ao empobrecimento material e subjetivo aos quais conduz o capitalismo. Por meio deles, o desafio consiste em construir uma perspectiva que perfile a comunidade como categoria para o reconhecimento e a canalização de certas dinâmicas sociais e políticas potencialmente emancipadoras.

\section{COMUNIDADE COMO FORMA DE VIDA ANCESTRAL}

Em primeiro lugar, diferentemente do que supunham as sociologias e políticas desenvolvimentistas, os vínculos e valores comunitários tradicionais não desaparecem com a modernização capitalista. Pelo contrário, em alguns casos, eles se fortalecem e são reativados quando as pessoas começam a resistir ao desenvolvimento. Esse é o caso de muitos povos indígenas e povoações camponesas em países como Bolívia, Equador, Colômbia, Guatemala e México, onde o comunitário constitui um modo de vida ancestral, sustentado na existência de uma base territorial comum, formas de produção e de trabalho solidário, práticas de autoridade e um repertório de costumes comunitários.

Nas últimas décadas tem ocorrido um processo de reindianização em vários países, ou seja, uma reativação de identidades ancestrais junto a estratégias de recuperação de territórios, costumes e formas de governo comunitário. A presença de sentidos, vínculos e práticas que reivindicam a dimensão comunitária também aparece nas fases iniciais e em conjunturas de mobilização de assentamentos urbano-populares, quando a precariedade de suas condições ou situações-limite de injustiça ativam processos de solidariedade e ajuda mútua.

Do mesmo modo, é possível perceber o surgimento de vínculos estáveis de solidariedade baseados na proximidade e em outras redes de apoio, como a origem regional ou a afinidade étnica. Nas fases iniciais de um assentamento popular, uma malha de relações é conformada. Surgem redes de solidariedade e lealdades que são constituídas como uma fortaleza coletiva e de resistência frente às dinâmicas massificadoras da vida urbana, da economia mercantil e das políticas adversas. 
Tanto a partir da investigação histórica e antropológica sobre as culturas andinas e mesoamericanas quanto a partir de algumas elaborações intelectuais indígenas, tais práticas e instituições comunitárias são expressão de um sistema cultural e de uma racionalidade singular radicalmente diferentes da racionalidade ocidental moderna. Por um lado, os estudos sobre os incas e as comunidades indígenas na Bolívia e no Peru mostram que os chamados costumes comunitários são sustentados em sistemas de reciprocidade presentes nos povos Quechua e Aymara; este é o caso do ayni, um sistema de trabalho de reciprocidade familiar entre os membros do ayllu, destinado a trabalhos agrícolas e à construção de casas, podendo ser traduzido como signo da felicidade coletiva, tanto em momentos de trabalho quanto de diversão e festas. Por outro lado, alguns antropólogos indígenas provenientes dos diversos pueblos de Oaxaca vem posicionando a categoria de comunalidade como um sistema relacional que caracteriza os povos indígenas. Para Floriberto Díaz (2004, p. 368), os elementos que definem a comunalidade são:

\section{A Terra como mão e como território.}

2. O consenso em assembleia para a tomada de decisões.

3. O serviço gratuito como exercício de autoridade.

4. O trabalho coletivo como um ato de recreação.

5. Os ritos e as cerimônias como expressão do dom comunal.

Para Martínez Luna (2004), outro líder e intelectual de Oaxaca, a comunalidade é uma experiência histórica que pode beneficiar o conjunto da humanidade. A comunalidade não é tanto uma ideologia, mas um modo de ser evidente nos povos indígenas, em última instância, também próprio de todas as culturas humanas.

\section{COMUNIDADES EMERGENTES EM SITUAÇÕES-LIMITE}

Encontramos processos similares em situações posteriores a catástrofes naturais ou humanas, como nos casos dos terremotos de Manágua (1976), México (1985) e Armênia (1999) ou em deslizamentos de terra e inundações ocasionados pelo fenômeno El Niño em centenas de localidades na Colômbia (2011). Nesses casos, ao enfrentarem a ausência e a tardia ou limitada ação 
institucional, os próprios afetados ativaram mecanismos de solidariedade e ação coletiva que permitiu sua reinvenção como comunidades.

Junto às formas de vida ou vínculos comunitários territoriais, podemos adicionar outras questões ligadas aos valores de justiça e aos sentidos compartilhados de futuro. Como exemplo, é possível citar os movimentos sociais que agrupam diferentes pessoas em torno da defesa do ambiente, do público, da reivindicação de seus direitos de gênero ou culturais. Tais coletivos, a partir de uma indignação comum, de suas ações conjuntas e da construção de agendas compartilhadas, constroem sentidos de pertença e vínculos comunitários que transcendem os interesses motivadores. As mencionadas comunidades intencionais surgem com o propósito deliberado de reorganizar sua convivência de acordo com valores idealmente elaborados, com base em crenças ou em novos marcos sociais de referência.

\section{EMERGÊNCIA DE NOVAS COMUNIDADES EMOCIONAIS}

Por outro lado, no contexto citadino vem surgindo formas de sociabilidade marcadas por fortes e intensos laços emocionais, seja em torno de espaços de massa ou de consumo cultural, como o caso das "culturas de juventude" - punk, rock, hip-hop -, das torcidas de futebol e dos múltiplos agrupamentos de adultos em relação a práticas culturais compartilhadas. Não se trata de uma solidariedade estável, tampouco de práticas orientadas por sentidos anticapitalistas, mas são gerados vínculos e lealdades interpessoais que não definidos pelo mero interesse ou benefício econômico.

Junto a esses sentidos de comunidade associados a dinâmicas sociais particulares, outros reivindicam o comunitário associado à necessidade de retomar o sentido ético da política a partir de ideais democráticos baseados na justiça, de tal modo que não existem excluídos "de fato" das comunidades políticas. Outros recorrem à noção de "bem comum", entendida como conjunto de assuntos comuns que tornam possível a convivência entre diversos atores sociais.

Essa emergência comunitária na América Latina exige uma conceptualização de comunidade que possibilite compreender e abarcar os mencionados modos de vida, os vínculos e os processos comunitários a partir 
das perspectivas emancipadoras próprias da educação popular. A seguir, serão mencionadas algumas ideias que podem servir para tal propósito.

\section{A COMUNIDADE NAS CIÊNCIAS SOCIAIS E O PENSAMENTO POLÍTICO ATUAL}

Comecemos por retomar as origens do uso de "comunidade" como conceito na nascente sociologia na segunda metade do século XIX. Naquele período, as sociedades europeias enfrentaram rápidos e radicais mudanças, como consequência das revoluções francesa e industrial. Uma dessas mudanças foi o modo de relacionam entre as pessoas. Ao passo que nas sociedades tradicionais a vida coletiva era articulada por laços subjetivos e compromissos baseados em valores, como a lealdade e o compromisso mútuo, nas cidades modernas e no mundo dos negócios as relações sociais eram sustentadas em contratos entre indivíduos e em acordos baseados na racionalidade utilitarista.

Essa metamorfose foi identificada por um jovem sociólogo alemão chamado Ferdinand Tönnies. Em 1887, no livro Comunidade e sociedade, ele introduziu a categoria comunidade para fazer referência a um tipo de relação social baseada em nexos subjetivos fortes, como os sentimentos, a proximidade territorial, as crenças e as tradições comuns expressas nos vínculos de parentesco, proximidade e amizade. Tais vínculos são opostos aos vínculos da sociedade, considerada como um tipo de relação social caracterizado pelo alto grau de individualidade e de impessoalidade procedentes do mero interesse.

Talvez a diferença fundamental entre comunidade e sociedade seja que, na comunidade, os seres humanos "permanecem essencialmente unidos, apesar de todos os fatores de dissociação", ao passo que, na sociedade, eles "estão essencialmente separados apesar de todos os fatores de unificação" (NISBET, 1996, p. 106). Para Tönnies, o comunitário e o societário não são inerentes a uma época nem a um coletivo social determinado. Em sua época também emergiam "comunidades de espírito" em torno de valores e projetos de vida compartilhados, como o socialismo, com o qual o autor se identificava.

Weber (1977, p. 33) percebe uma ação social que "se inspira em um sentimento subjetivo dos participantes para constituir um todo". Os vínculos 
comunitários também geram um sentido de pertença baseado em "todo tipo de fundamento afetivo, emotivo e tradicional". Ele também adverte que nem toda participação implica necessariamente comunidade. O habitar em um mesmo lugar ou a pertença à mesma etnia não implica necessariamente a presença de vínculos ou sentimentos subjetivos de pertença coletiva.

Essas elaborações têm validade na medida em que permitem criticar as relações continuamente promovidas pelo capitalismo, bem como questionar o pressuposto de que qualquer povoação localizada já é uma comunidade. Além disso, isso permite que perguntemos o quanto de comunidade há em qualquer vizinhança ou aldeia camponesa, já que o tema remete à qualidade dos vínculos. De todo modo, o fato de algo impulsionar ações adjetivadas como comunitárias não significa que as ações partem de comunidades já dadas, mas que buscam promover sentidos e vínculos comunitários.

\section{A COMUNIDADE COMO DÍVIDA}

Outra perspectiva de comunidade é proposta por Roberto Esposito (2003). Ao fazer referência a sua etimologia latina, ele revela que, na palavra communitas, o sufixo munus, entendido como dom, remete a uma ausência, uma obrigação ou dívida compartilhada, e não à posse de algo em comum. Assim, a comunidade não seria um conjunto de indivíduos que compartilham propriedades comuns, mas um compromisso compartilhado entre sujeitos singulares do qual se tornam solidariamente responsáveis e que deve ser renovado permanentemente. Desse modo, o oposto de communitas é inmunitas, que faz referência àquele que não quer assumir o fardo, a responsabilidade de e com os outros.

Essas ideias de Esposito também podem ser pertinentes para abarcar e potencializar as práticas e processos comunitários atuais que emergem e são sustentados por sonhos e compromissos compartilhados que não se esgotam na consecução de reivindicações ou na existência de algumas utopias compartilhadas.

Outra interessante contribuição do pensamento contemporâneo provém do intelectual espanhol José Ángel Begúa (2015, p. 39), que equipara a categoria comunidade com a de comum, de pessoas: "o demos, as pessoas simples, as multidões são o húmus do social, a origem de todo o atual e possível. Em sua 
forma mais elementar, trata-se do estar-junto ou estar um com o outro, sendo importante nesta segunda fórmula o com". Ele retoma Esposito (2005) para relembrar que etimologicamente o termo comunidade deriva do latim munus, que significa fardo ou dívida que deve ser intercambiada entre os sujeitos. Na medida em que se opõe à inmunitas, a comunidade tem a ver com um intenso e agitado estado de contágio e propagação: ela se converte em um estar com e entre nós, no nexo invisível que nos torna humanos. Assim, a comunidade remete ao inaugural, ao potencial criativo do instituinte. Então, não se trata de algo apropriável por nenhum poder, mas que permite que as posições e as afinidades circulem, obriguem sua revisão contínua para que não sejam institucionalizadas. Esse sentido de comunidade corresponde a certos momentos de efervescência social e solidariedade que Turner (1998) denomina communitas, que se contrapõe à "estrututra" e ao instituído socialmente.

Essas contribuições sobre o caráter instituinte do comunitário são muito pertinentes para abarcar situações, conjunturas ou processos nos quais os sentidos são ativados e reativados. Eles ajudam a explicar vínculos e práticas de caráter solidário quando, ao calor de uma adversidade e de um processo social emergente, é desdobrado o potencial criativo dos coletivos.

\section{DESAFIOS COMUNITÁRIOS PARA AS PEDAGOGIAS EMANCIPADORAS}

Quais são os sentidos e as implicações desta percepção de comunidade para o campo da educação popular e das outras formas de educação, bem como seu potencial emancipador, particularmente as articulações e interações com coletivos, processos de ideais "comunitários"? Consideremos a comunidade como modo de vida, vínculo; como valor e horizonte de um futuro que se opõe ao capitalismo. A partir dessa perspectiva, a educação popular é uma prática pedagógica emancipadora.

Hoje há advertências sobre uma série de usos e abusos da categoria "comunidade" no contexto social e político hegemônico e em suas alternativas. Por um lado, há países onde as políticas sociais estão subordinadas ao modelo neoliberal. Nesses lugares, os programas e os projetos buscam integrar de maneira subordinada as populações pobres rurais e urbanas à economia e à sociedade capitalista. 
Sob o rótulo de "desenvolvimento comunitário" ou "participação comunitária", aquelas populações são instrumentalizadas como "usuários", "beneficiários" ou "clientes" da ação estatal. Essas políticas "comunitárias" debilitam os laços e os valores comunitários, fomentando relações assistencialistas e clientelistas, bem como a passividade, o individualismo e a rivalidade entre os grupos populares.

Por outro lado, a partir de iniciativas sociais e política progressistas, altruístas e até mesmo alternativas, o qualificativo "comunitário" foi generalizado para nomear diferentes práticas de ação social com grupos populares. Sustentase que, pelo fato de habitar um mesmo território e compartilhar carências e necessidades comuns, os grupos já são comunidades. Os mencionados coletivos assumem como homogêneas algumas propostas de acampamento e de trabalho comunitário, bem como de "educação comunitária", atribuindo a elas uma vontade e uma consciência comuns que devem ser mobilizadas em função dos interesses e das finalidades da mudança a ser promovida.

Diante dessas concepções, convém a consideração de uma perspectiva que reivindique o potencial impugnador, instituinte, emancipador e pluralista. Uma perspectiva que retome o sentido político, ético, crítico e emancipados do comunitário que poderia ser observado na solidariedade e no compromisso entre sujeitos singulares.

Os sentidos de comunidade expostos oferecem a possibilidade de que assumamos o conceito como uma categoria do pensamento crítico, que torna visível aqueles processos, ações e experiências que evidenciam ou promovem vínculos, significados compartilhados e ambientes orientados para a solidariedade, a reciprocidade, o compromisso mútuo e a produção de um sentido de pertença, com o poder de questionar ou de constituir a proposta como alternativa à racionalidade capitalista.

Nesse sentido, será "comunitária" uma política ou ação educacional que promova vínculos, subjetividades e valores comunitários. Trata-se de um processo de criação e fortalecimento permanente do tecido social e de potencialização da capacidade de agência de sujeitos pessoais e coletivos sociais unidos entre si e em torno de diferentes fatores e circunstâncias territoriais, culturais, geracionais, crenças e visões de futuro compartilharas. As comunidades não podem pressupor que são estruturas dadas de uma vez por 
todas, mas devem pressupor que estão em um processo de permanente evolução e aprendizagem.

Essa perspectiva implica que os indivíduos que pretendem impulsionar projetos ou ações de promoção, participação ou educação comunitárias incorporem, de maneira consciente, dispositivos que gerem e alimentem vínculos, subjetividades e valores comunitários como a produção de narrativas e símbolos que afirmem o sentido de pertença. Oferecer uma reflexão conjunta sobre o que significa ser uma comunidade e fazer parte dela também permite identificar os fatores e os atores que atentam contra os vínculos e os valores coletivos e, ademais, promove uma formação em torno das tradições, dos valores e dos ideais comunitários.

Enfim, as pedagogias emancipadoras podem servir de estímulo para que diferentes expressões de comunidade incorporem práticas reflexivas sobre seu caráter e sua potencialidade emancipadora ao introduzir espaços de reflexão sobre suas dinâmicas, relações e subjetividades constituintes. Quando são gerados esses processos reflexivos sobre os fatores, os exemplos e as potencialidades que definem vínculos e identidades coletivas, são configuradas "comunidades críticas" (KEMMIS, 1993).

Tradução: Felipe Ziotti Narita

O artigo foi publicado originalmente na revista Praxis Pedagógica, Bogotá, v. 18, n. 22, 2018. A presente tradução foi autorizada pelo autor, a quem agradecemos o pronto interesse e a participação em nossa coletânea.

\section{REFERÊNCIAS}

BARCELLONA, P. Postmodernidad y comunidad: el regresso de la vinculación social. 3. Ed. Valladolid: Trota, 1999.

BERGÚA, J. A. Postpolítica: elogio del gentío. Madrid: Biblioteca Nueva, 2015.

DÍAZ, J. F. "Comunidad y comunalidad". Diálogos en Acción, Cidade do México, 2004.

DURAND, G. La imaginación simbólica. Buenos Aires: Amorrortu, 2000.

CUEVAS, P. "Decolonizar la educación popular/resignificar la comunidad". Aportes, v. 60, p. 123-136, 2016. 
ESPOSITO, R. Communitas: origen y destino de la comunidad. Buenos Aires: Amorrortu, 2003.

KEMMIS, S. La formación del profesorado y la extensión de comunidades críticas. Investigación en la Escuela, v. 19, p. 15-38, 1993.

MAFFESOLI, M. El tiempo de las tribus. Barcelona: Ikaria, 1990.

LUNA, J. Comunalidad y desarrollo. Diálogos en Acción, Cidade do México, 2004.

MEDINA MELGAREJO, P. Pedagogías insumisas: movimientos políticopedagógicos y memorias colectivas de educaciones otras en América Latina. México: Juan Pablo Editor, 2015.

NISBET, R. La formación del pensamiento sociológico. Buenos Aires: Amorrortu, 1996.

ORTEGA, P. Pedagogía de la memoria para un país amnésico. Bogotá: Universidad Pedagógica Nacional, 2016.

RUBIO, G. Educación y memoria: tensiones y desafíos de una propuesta, Nómadas, v. 15, n. 1, p. 163-175, 2007.

SKLIAR, C.; LARROSA, J. Experiencia y alteridad en educación. Buenos Aires: Flacso, 2011.

TÖNNIES, F. Comunidad y asociación. Madrid: Península, 1887.

TORRES, A. El retorno a la comunidad: problemas, debates y desafíos de vivir juntos. Bogotá: Cinde, El Búho, 2013.

TORRES, A. Educación popular y movimientos sociales en América Latina. Buenos Aires: Editorial Biblos, 2016.

TURNER, V. El proceso ritual: estructura y antiestructura. Madri: Taurus, 1998.

WALSH, C. Pedagogías decoloniales: prácticas insurgentes de resistir, (re)existir y (re)vivir. Quito: Abya Yala, 2013.

WEBER, M. Economía y sociedad. México: Fondo de Cultura Económica, 1944. 